\section{REVIEW ARTICLE}

\author{
T.D. Uschold
}

D. Fusco

R. Germain

L.M. Tumialan

S.W. Chang

\title{
Cervical and Lumbar Spinal Arthroplasty: Clinical Review
}

\begin{abstract}
SUMMARY: In contrast to cervical and lumbar fusion procedures, the principal aim of disk arthroplasty is to recapitulate the normal kinematics and biomechanics of the spinal segment affected. Following decompression of the neural elements, disk arthroplasty allows restoration of disk height and maintenance of spinal alignment. Based on clinical observations and biomechanical testing, the anticipated advantage of arthroplasty over standard arthrodesis techniques has been a proposed reduction in the development of symptomatic ALD. In this review of cervical and lumbar disk arthroplasty, we highlight the clinical results and experience with standard fusion techniques, incidence of ALD in the population of patients with surgical fusion, and indications for arthroplasty, as well as the biomechanical and clinical outcomes following arthroplasty. In addition, we introduce the devices currently available and provide a critical appraisal of the clinical evidence regarding arthroplasty procedures.
\end{abstract}

ABBREVIATIONS: ACDF = anterior cervical diskectomy and fusion; ALD = adjacent-level degenerative disease; $\mathrm{AOR}=$ axis of rotation; $\mathrm{BAK}=$ Bagby and Kuslich; $\mathrm{DDD}=$ degenerative disk disease; $\mathrm{HO}=$ heterotopic ossification; NDI = neck disability index; ODI = Oswestry Disability Index; $\mathrm{RCT}=$ randomized controlled trial; ROM = range of motion; SF-36 = Short Form 36; UHMWPE = ultrahigh molecular weight polyethylene; VAS = Visual Analog Scale

A nterior cervical fusion techniques were first introduced and popularized by Cloward, ${ }^{1}$ Bailey and Badgley, ${ }^{2}$ Robinson, ${ }^{3}$ Smith and Robinson, ${ }^{4}$ and others in the late 1950 s and early 1960s. Today, anterior cervical diskectomy with interbody fusion and plating is the predominant technique used in the treatment of symptomatic disk herniations, spondylosis, segmental instability, selected traumas, malalignment, and, more controversially, axial neck pain. The nuances of patient selection, surgical technique, and choices of interbody device and instrumentation are beyond the scope of the current review. When one broadly considers anterior cervical arthrodesis procedures, rates of symptomatic improvement and radiographic fusion are extremely favorable for single- and multilevel constructs for the range of indications mentioned above. $^{5,6}$

Although clinical experience with the first cervical arthroplasty prototype was initially reported in 1966 by Fernström ${ }^{7}$ and expanded by Reitz and Joubert, ${ }^{8}$ this alternative to fusion fell into early disfavor due to hardware-related complications and postoperative adjacent-level hypermobility. ${ }^{9,10}$ With time, however, motion-preservation strategies were reconsidered largely due to clinical and radiographic observations of progressive degenerative disease at levels immediately adjacent to surgically fused segments (ALD). The distinction between purely radiographic and symptomatic (myelopathy, radiculopathy, or myeloradiculopathy) ALD is critical to our understanding of this process. Unfortunately, few studies have been adequately designed or powered to allow definitive conclusions about the pathophysiology, natural history, or incidence of ALD. ${ }^{11}$ In 1996 , Wu et al ${ }^{12}$ reported a statistically

From the Division of Neurological Surgery, Barrow Neurological Institute, St. Joseph's Hospital and Medical Center, Phoenix, Arizona.

Please address correspondence to Timothy D. Uschold, MD, Barrow Neurological Institute, 350 West Thomas Rd, Phoenix, AZ 85013; e-mail: timothy.uschold@bnaneuro.net

Indicates open access to non-subscribers at www.ajnr.org

http://dx.doi.org/10.3174/ajnr.A2758 higher rate of radiographic degenerative changes, including anterior osteophytes and disk herniations, in 68 patients treated with 1- or 2-level anterior cervical fusions compared with asymptomatic matched controls at 3-year follow-up. Although such results seem to implicate surgical arthrodesis in the development of ALD, interpretation must allow the limitations of such a matched case-control study.

Radiographic evidence alone of ALD has been reported to occur in as many as $92 \%$ of patients at 5-year follow-up. ${ }^{13}$ Perhaps the most compelling data are derived from larger retrospective series. In 1980, Lunsford et $\mathrm{al}^{14}$ reported a series of 253 patients treated for disk herniations with at least 1-year follow-up. A $6.7 \%$ reoperation rate for newly symptomatic levels was reported, though adjacent-level pathology per se was not specifically tabulated. Hilibrand et $\mathrm{al}^{15}$ calculated a $2.9 \%$ annual risk of symptomatic ALD from their review of 374 surgically treated patients. Development of ALD, however, appeared complex and likely related to preoperative imaging findings at adjacent levels as well as to the location of the level affected. ${ }^{15}$ Most interesting, Goffin et $\mathrm{al}^{13}$ were able to demonstrate a similar rate of ALD in younger patients with trauma compared with older patients with degeneration following anterior cervical arthrodesis. The primary difficulty among all such studies has been controlling for the natural rate of degenerative changes in the aging spine, particularly among a subgroup of symptomatic patients who have already demonstrated surgically significant degeneration.

Cadaveric testing has provided similarly compelling, though complex and controversial, evidence for the biomechanical factors involved in the development of ALD following arthrodesis. Illustrating the complexity of the issue, studies have reported increased intradiskal pressures and segmental motion that are dependent on both the location of the adjacent level (superior versus inferior to the fused segment) and the type of loading used (flexion versus extension). ${ }^{16}$ Studies additionally reveal that the degree of lordosis achieved during fusion significantly alters adjacent-level range of motion, ${ }^{17}$ and that in some cases, segmental mobility may be maximally 

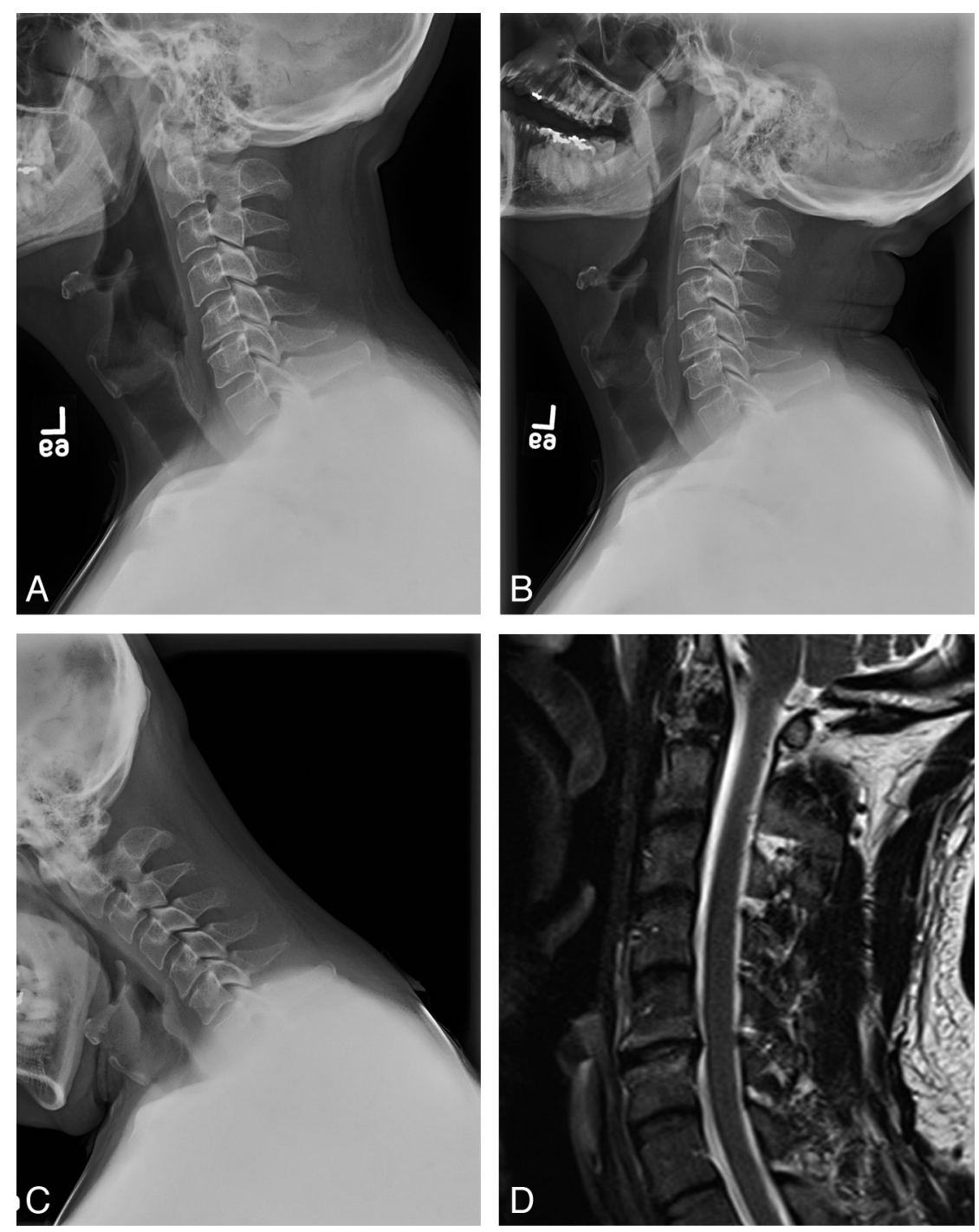

Fig 1. Ideal candidate for cervical arthroplasty. $A$, Lateral radiograph depicting minimal facet arthropathy and degenerative disease. $B$ and $C$, Extension $(B)$ and flexion $(C)$ radiographs depicting normal segmental motion at the index level and throughout the cervical spine. $D$, Sagittal T2-weighted MR image depicting single-level degenerative disk disease, endplate changes, relative preservation of disk height, and posterior disk bulge without marked osteophyte formation.

increased at levels distant from the index level. ${ }^{18}$ Cadaveric studies have also supported the finding that arthrodesis generally results in increased adjacent-level intradiskal pressures ${ }^{19,20}$ and statistically significant changes in adjacent-level motion, ${ }^{21,22}$ compared with arthroplasty under the same testing paradigms. In their review, Bartolomei et $\mathrm{al}^{11}$ reported that critics of cadaveric studies have noted the technique's limitations, including the following: the inability to simulate true bony fusion, the ability to investigate only immediate rather than long-term functional changes, the failure to account for the in vivo effects of stabilizing paraspinal musculature, and the inability to assess the clinical relevance of such induced changes.

Total disk arthroplasty cannot uniformly supplant arthrodesis but is an alternative for a subset of patients who would otherwise require anterior fusion. Candidates are adult patients who present after a period of failed conservative therapy with radiculopathy or myelopathy due to subaxial compressive pathology. Exclusion criteria derived from clinical trials are in some cases device-specific but generally include the following: $\geq 3$ surgical levels, spondylolisthesis, cervical instability as documented with dynamic imaging, severe loss of disk height, adjacent prior fusion, pregnancy, axial neck pain alone without neurologic symptoms, local infection, local tumor or metastasis, cervical trauma, osteoporosis, chronic steroid use, and notable systemic disease (eg, rheumatoid arthritis, insulin-dependent diabetes mellitus, malignancy, and so forth). ${ }^{23-25}$ In relative contrast to the lumbar spine, the goal of cervical arthroplasty is to preserve rather than to restore normal spinal kinematics. As a result, patients with existing ankylosing disease or fused segments are excluded. ${ }^{26}$ Reconstitution of the full mobile spinal segment similarly requires functional facet articulations, and patients with significant degeneration or fusion elsewhere within the trijoint complex are, therefore, also excluded (Fig 1).

In 2008, Auerbach et $\mathrm{al}^{23}$ retrospectively reviewed 167 consecutive patients undergoing cervical spine procedures and reported that $43 \%$ of patients would be candidates for total disk replacement based on published recommendations. That number would have increased to $47 \%$ if adjacent-level disease 


\begin{tabular}{|c|c|c|c|c|c|c|c|c|}
\hline \multicolumn{9}{|c|}{ FDA-approved cervical and lumbar arthroplasty devices } \\
\hline Device & Application & Design & Biomaterials & Endplate & Fixation & Kinematics & $\begin{array}{l}\text { FDA IDE } \\
\text { Approval }\end{array}$ & Manufacturer \\
\hline Prestige ST & Cervical & $\begin{array}{l}\text { Uniarticular ball } \\
\text { and trough }\end{array}$ & $\begin{array}{l}\text { Metal-on-metal } \\
\text { articulation, } \\
\text { stainless steel }\end{array}$ & $\begin{array}{c}\text { Roughened } \\
\text { surface }\end{array}$ & $\begin{array}{l}\text { Vertebral body } \\
\text { screws }\end{array}$ & Unconstrained & July 2007 & Medtronic \\
\hline Bryan & Cervical & Biarticular & $\begin{array}{l}\text { Titanium alloy } \\
\text { shells with } \\
\text { polyurethane } \\
\text { nucleus, saline } \\
\text { lubricant }\end{array}$ & $\begin{array}{l}\text { Applied porous } \\
\text { coating }\end{array}$ & Milled, press-fit & Unconstrained & May 2009 & Medtronic \\
\hline ProDisc-C & Cervical & $\begin{array}{l}\text { Uniarticular ball } \\
\text { and socket }\end{array}$ & $\begin{array}{l}\text { CCM endplate } \\
\text { with UHMWE } \\
\text { inlay, metal-on- } \\
\text { polyurethane } \\
\text { articulation }\end{array}$ & $\begin{array}{c}\text { Roughened } \\
\text { titanium }\end{array}$ & Central keel & Semi-constrained & $\begin{array}{l}\text { December- } \\
2007\end{array}$ & Synthes Spine \\
\hline CHARITÉ & Lumbar & $\begin{array}{l}\text { Biarticular ball } \\
\text { and socket }\end{array}$ & $\begin{array}{l}\text { CC endplates with } \\
\text { UHMWPE } \\
\text { sliding core }\end{array}$ & $\begin{array}{l}\text { Titanium and } \\
\text { calcium } \\
\text { phosphate } \\
\text { plasma spray }\end{array}$ & $\begin{array}{l}6 \text { Fixation teeth } \\
\text { at cranial/ } \\
\text { caudal } \\
\text { endplates }\end{array}$ & Unconstrained & $\begin{array}{l}\text { October- } \\
2004\end{array}$ & Depuy Spine \\
\hline ProDisc-L & Lumbar & $\begin{array}{l}\text { Uniarticular ball } \\
\text { and socket }\end{array}$ & $\begin{array}{l}\text { CCM endplates } \\
\text { with UHMWPE } \\
\text { insert }\end{array}$ & $\begin{array}{l}\text { Titanium plasma } \\
\text { spray }\end{array}$ & $\begin{array}{l}\text { Large central } \\
\quad \text { keel, } 2 \\
\text { lateral spikes }\end{array}$ & Semi-constrained & $\begin{array}{r}\text { August } \\
2006\end{array}$ & Synthes Spine \\
\hline
\end{tabular}

Note:-CCM indicates cobalt-chrome-molybdenum, CC, cobalt-chrome alloy; IDE, Investigational Device Exemption.

after prior fusion was removed as a contraindication. These figures, however, represent significant overestimates based on our clinical experience. There are currently a few published studies with small sample sizes that have reported cervical disk replacement after prior adjacent fusion, and preliminary results have compared favorably with those of fusion. ${ }^{27-30}$

Total disk arthroplasty devices may be classified according to modular versus nonmodular design, device endplate treatment, fixation properties, articular surface composition, articular design (uniarticular, biarticular, nonarticular), as well as kinematics. ${ }^{31-33}$ Currently available implants and selected devices under trial in the United States are presented in the Table. Methods of endplate fixation by order of increasing pullout strength include serrated teeth, $>1-\mathrm{mm}$ toothed ridges or keels, and vertebral body screws. All modalities were tested as superior to the tricortical iliac crest graft alone but inferior to cage placement with anterior plating in a synthetic spine model. ${ }^{31}$ Press-fit designs were not tested. Endplates may also be coated with a variety of osteoconductive biologic or metal alloy substrates to facilitate bony ingrowth and long-term stability. $^{34}$

$\mathrm{HO}$, or bony overgrowth, has been reported to occur in as many as $59 \%$ and $76 \%$ of patients at $1-{ }^{35}$ and 3 -year follow-up, respectively. ${ }^{36}$ Although some deterioration in the range of motion with time is not atypical or necessarily unexpected, $\mathrm{HO}$-related rates of clinically relevant hypomobility or bony union across the device have been incompletely evaluated. Early exuberant bone incorporation is typically addressed by a short course of postoperative nonsteroidal anti-inflammatory medications administered to all patients.

Articular surfaces include varying combinations of metal alloy (eg, titanium, stainless steel, cobalt, and chromium), polymer composite, and ceramic. Sekhon et $\mathrm{al}^{37}$ found that devices composed of cobalt-chrome-molybdenum alloys obscured visualization of index and adjacent levels on MR imaging compared with titanium alloy or composite alternatives. This effect, however, was dependent on magnet strength in another study by Antosh et al. ${ }^{38}$ Although well-described in reference to large-joint orthopedic prostheses ${ }^{39}$ and less commonly after lumbar arthroplasty, ${ }^{40}$ wear-related failure, debris accumulation, ${ }^{41}$ and aseptic loosening have been uncommonly encountered following cervical arthroplasty. Biomaterials and prosthesis design are key to the long-term viability of any disk implant, and the risk of device fatigue may be more negligible in the cervical region due to lower stresses, loads, and mobility compared with the lumbar region. ${ }^{32,34,42}$ The long-term clinical effects of cervical prosthesis osteointegration and wear, however, have been incompletely evaluated. ${ }^{43}$

Total artificial disk implants are categorized kinematically as constrained, semiconstrained, and unconstrained on the basis of their ability to restrict or permit segmental motion relative to normal physiologic parameters. Bearing material, position, joint configuration (eg, uniarticular ball and socket, uniarticular ball and trough, biarticular ball and socket, or biarticular saddle configuration), and geometry (eg, spheric, toroidal, or ovate surface) of the articulation create a unique kinematic profile for each device. Constrained implants provide superior stability but require greater precision during surgical placement to adequately match the device's fixed axis of rotation to the spinal level affected. Unconstrained implants rely on axial ligaments, muscle, and tensioning support to provide stability, but their unfixed axis of rotation may distribute loads away from the bone-device interface. Optimal device kinetics have not been established on the basis of the available short-term clinical and biomechanical studies. Device selection is highly individualized, and successful reproduction of physiologic kinematics must consider multiple factors, including facet loading, disk height, device design, and position of the implant within the interspace (Fig 2). ${ }^{34,44,45}$

The Prestige-ST (Medtronic, Memphis, Tennessee), ProDisc-C (Synthes Spine, West Chester, Pennsylvania), and Bryan artificial cervical disks (Medtronic) were approved for implantation in the United States between 2007 and 2009 following the publication of FDA Investigational Device Exemp- 

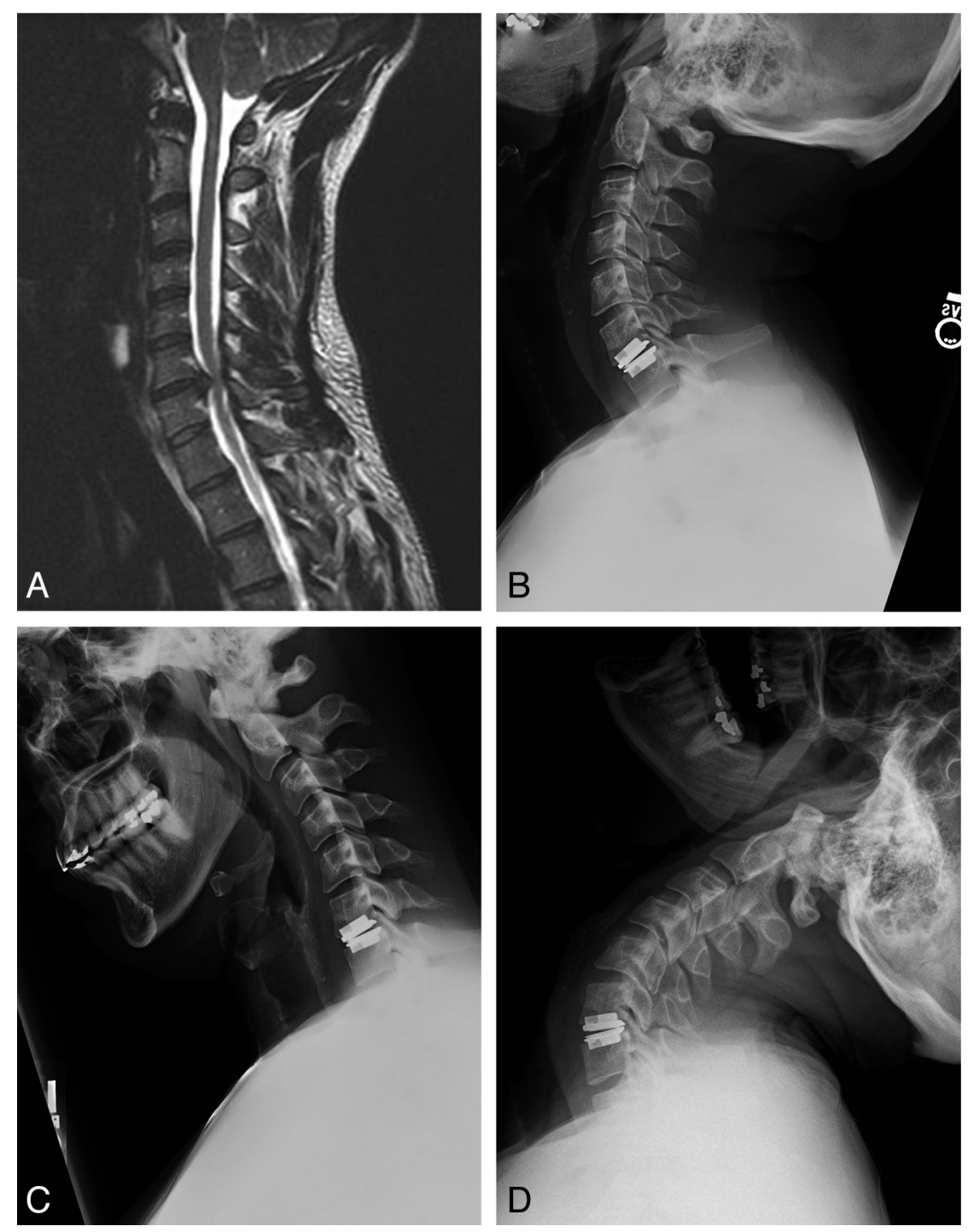

Fig 2. Case illustrating the importance of patient positioning for optimized biomechanics. $A, A$ 36-year-old man with radicular symptoms referable to this $C 6-7$ paramedian disk herniation seen on a sagittal T2-weighted MR image. The patient was positioned in mild cervical lordosis during ProDisc-C placement. $B$ and $C$, As a result, postoperative extension ( $B$ ) and flexion $(C)$ radiographs obtained at 6 months revealed no movement at the instrumented level. $D$, Segmental motion was evident only with maximal extension beyond the typical physiologic range of motion.

tion trials (Table). ${ }^{46-48}$ Adult patients were enrolled on the basis of single-level radicular symptoms referable to degenerative disk disease and were randomized to receive control ACDF versus investigational arthroplasty device implantation. These studies were designed and powered as prospective multicenter nonblinded 2-year noninferiority efficacy and safety trials. In 2007, Mummaneni et al ${ }^{46}$ reported on 541 patients treated at 32 centers. They found statistically significant higher rates of neurologic success $(P=.005)$ and lower rates of adjacent-level surgeries ( $1.1 \%$ versus $3.4 \%, P=.0492)$ with Prestige ST (Medtronic) placement compared with ACDF at 24-month follow-up. Re-examination of the data by Botelho et $\mathrm{al}^{49}$ however, by using number-needed-to-treat analysis, failed to show statistical significance for adjacent-segment disease necessitating surgery (Fig 3). In addition, at 5-year follow-up on the same cohort of patients, rates for surgery at adjacent levels were lower for the investigational group but not statistically significant $(4.9 \%$ versus $2.9 \%, P=.376) .{ }^{50}$ The implant was noted to maintain motion at the index level, averaging more than $6.5^{\circ}$ at last follow-up.

Murrey et $\mathrm{al}^{48}$ reported statistically significant results favoring arthroplasty with the ProDisc-C device in terms of narcotic use and the need for secondary surgery at last follow-up. In this study, only 1 patient with fusion underwent secondary surgery for ALD. Most interesting, only $84.4 \%$ of patients in the investigational arm met criteria for motion preservation at the index level at 2-year follow-up. In a Bryan cervical disk trial reported by Heller et al, ${ }^{47}$ statistically significant differences favoring arthroplasty were noted for NDI scores, time to return to work, and "overall success" (defined as $\geq 15$-point increase in the NDI score, stable or improved neurologic status, no need for a repeat operation, and absence of a surgical or implant-related adverse event). An analysis of secondary outcome measures also confirmed noninferiority and, in some instances, indicated a nonsignificant trend favoring arthroplasty. Patients with myelopathy were included in this trial, 

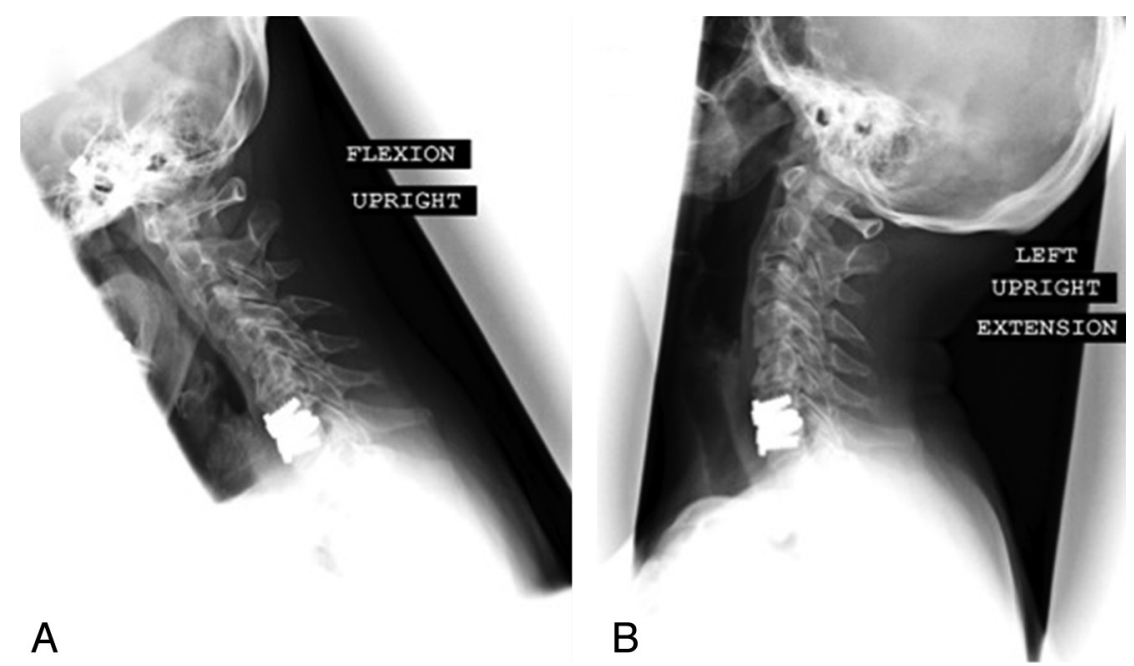

Fig 3. Dynamic flexion $(A)$ and extension $(B)$ postoperative lateral cervical radiographs following Prestige-ST arthroplasty in a 56-year-old woman. Segmental range of motion is preserved by the Prestige-ST device. Despite motion preservation, this particular patient ultimately required CT myelography, removal of the arthroplasty device, and 2-level anterior cervical fusion for symptomatic adjacent-level disease 1 year after arthroplasty.

and despite unanticipated crossovers from the investigational to control arms, the superiority of arthroplasty in terms of "overall success" remained robust in intent-to-treat analysis. In terms of artificial disk long-term mobility, the authors noted that $7 \%-8 \%$ of investigational patients displayed $<2^{\circ}$ of motion at each follow-up time point, but no single patient remained consistently below that threshold at all time points to indicate reliable hypomobility. Last, radiographic or symptomatic adjacent-level disease was not reported.

Despite the findings of many of these published studies, definitive conclusions regarding the utility of arthroplasty are limited due to the following factors affecting each trial: noninferiority study design, short-term follow-up, operator bias due to the impossibility of blinding, patient and assessor bias due to unblinded design, failure to specifically address ALD as a primary outcome measure, and the use of survey data. In fact, in 2010 a meta-analysis of randomized controlled trials concluded that cervical disk prostheses were unjustified compared with fusion. ${ }^{51}$

The devices introduced above, new investigational implants, and additional secondary end points have been studied through subset analyses, subsequent follow-up studies, or within smaller trials. ${ }^{52-57}$ Clinical studies specifically addressing ALD as a primary outcome, however, remain sparse. Anderson et $\mathrm{al}^{58}$ reported that World Health Organization grade 3 or 4 events as well as repeat operations were more common for the arthrodesis group in a review of the FDA Investigational Device Exemption Bryan disk evaluation data. However, the difference in the number of adjacent-level repeat operations between the 2 groups did not reach significance. Jawahar et $\mathrm{al}^{59}$ examined the incidence of ALD among 93 patients randomized to 1- or 2-level ACDF versus arthroplasty, pooling their cohort from 3 different device FDA Investigational Device Exemption clinical trials. They reported no statistically significant difference in the development of ALD (15\% controls, $18 \%$ investigational arms) at mean follow-up of 36.4 months. ALD was defined as clinical and radiologic evidence of adjacent level degeneration requiring "active intervention." Unfortunately, because the results involve data pooled from multiple independent device trials, with varied surgical indications and a high incidence of ALD in both arms, there remains significant room for additional interpretation. Last, as mentioned previously, the recently published 5-year follow-up data for 271 of the patients enrolled in the original Prestige-ST FDA Investigational Device Exemption trial also failed to demonstrate a statistically significant difference for the rates of surgeries performed for ALD (2.9\% versus 4.9\%, arthroplasty versus arthrodesis). ${ }^{50}$

\section{Summary}

Critical review of the literature suggests that total cervical disk arthroplasty is a comparatively safe and effective alternative to anterior fusion for appropriately selected patients in the short term. With a reduction in the development of symptomatic ALD as the primary goal of arthroplasty, however, there is no compelling long-term level 1 clinical evidence to suggest its superiority for routine use over fusion. Moreover, the shortand long-term effects of motion preservation on the posterior elements (eg, ligamentum flavum, facet joints) have not been adequately studied. Marketed arthroplasty implants have a broad range of biomechanical and kinematic properties, and the long-term clinical consequences of these alternative designs are also incompletely understood. In the opinion of the authors, evidence showing clear superiority for cervical disk replacement over fusion will be difficult to generate due to the excellent results currently achieved with ACDF; the biomechanical complexity of the trijoint complex; and the requirements for rigorous clinical study designs with longer-term follow-up, larger study populations, and standardized means of evaluating competing devices.

\section{Lumbar Arthroplasty}

Low-back pain is a major health problem in Western countries, the major causes of which are thought to be DDD and facet arthropathy. ${ }^{60,61}$ It has been hypothesized that through disk dehydration, annular tears, and loss of disk height, DDD can result in abnormal motion of the involved segment and biomechanical instability causing pain. Similarly, chronic 
facet stress leads to hypertrophy, osteophyte formation, distortion of innervating elements, pathologic motion within the facet capsule, and pain. ${ }^{62,63}$ While conservative treatment modalities such as physical therapy, massage, and oral medication regimens are initially used, incomplete pain control often leads patients and health care providers to consider surgical intervention. Lumbar fusion or arthrodesis has been considered the criterion standard surgical treatment for DDD and facet arthropathy. ${ }^{64}$ This can be accomplished via multiple surgical corridors (eg, posterior, posterolateral, lateral retroperitoneal, anterior retroperitoneal) and may involve fusion across any or all of the 3 lumbar columns via screw/rod constructs, interbody devices, clamp/plating systems, and posterolateral autograft/allograft supplementation. The theoretic means by which lumbar arthrodesis achieves pain relief is the elimination of motion at the fused segment, regardless of which column is serving as the pain generator.

The long-term results of lumbar spinal fusion have been mixed. ${ }^{62,65,66}$ While selected patients experience decreased pain and disability versus conservative treatment, ${ }^{65}$ not all patients achieved significant pain relief, and a proportion of patients developed pain caused by further degeneration at levels not treated during the initial operation (ie, ALD). Furthermore, infectious complications are common, seen in $10 \%-$ $40 \%$ of patients. ${ }^{67}$ Despite the lack of convincing prospective evidence supporting spinal fusion for pain relief, ${ }^{68,69}$ the number of fusion procedures performed is continually increasing, with an estimated 77\% increase between 1996 and 2001. ${ }^{70}$

As an alternative surgical procedure, total lumbar disk replacement or lumbar arthroplasty was developed as a means of relieving pain while restoring and maintaining segmental load transfer, sagittal balance, and the spinal segment motion. ${ }^{71-73}$ It was additionally hypothesized that the use of these devices would decrease the incidence of fusion-induced degeneration at adjacent segments, further improving clinical outcomes. The concept of lumbar disk replacement as an alternative to fusion initially gained momentum following the success of total knee and hip arthroplasty. ${ }^{74,75}$ Since the first described total disk replacement in the late $1950 \mathrm{~s},{ }^{7}$ multiple disk replacement prostheses have been designed for use in the lumbar spine. These devices, however, carry significant cost and have a variable track record for both safety and clinical outcomes. ${ }^{76}$ In this section of the review, we will examine the evidence supporting the efficacy of these implants as a durable treatment for chronic low back pain attributed to degenerative disease in the lumbar spine.

Degeneration of the intervertebral disk is an inevitable consequence of aging, bipedal ambulation, and upright posture. It is widely accepted that disk degeneration is caused, at least in part, by the gradual deterioration of tissues subject to these constant physiologic stresses. ${ }^{76}$ Additionally, it has been well established via in vitro modeling that immobilization of a spinal motion segment further increases adjacent segment stress, as manifest by increased intradiskal pressures and an angular range of motion. ${ }^{77-80}$ Several studies, however, have identified multiple potential independent risk factors for the development of ALD, including age, postmenopausal status in women, diagnosis of regional lumbar stenosis, osteoporosis, and postfusion sagittal and coronal malalignment (eg, transition syndrome). ${ }^{81-84}$ Multiple longitudinal studies of patients receiving lumbar fusion (see below) have also failed to identify elevated rates of ALD. This failure of in vitro models to predict the clinical consequences of fusion is generally thought to be due to the inability of the pure moment loads used in laboratory models to adequately represent the more complex spinomuscular loading schemes observed in vivo. ${ }^{85}$

In 1978, Frymoyer et $\mathrm{al}^{86}$ reported their experience in a group of 207 patients ( $n=143$, fusion-group) followed for at least 10 years (mean, 13 years) after lumbar disk surgery. While radiographic signs of adjacent segment degeneration were more common in the fused group, there were no statistically significant clinical differences between the groups at last follow-up. Indeed, fewer (30\%) of the fusion patients required further surgery compared with patients treated without fusion (37\%). Nonetheless, selection bias and inherent limitations with case-control matching prevent definitive interpretation of these data. Seitsalo et $\mathrm{al}^{87}$ studied a group of 227 patients treated for isthmic spondylolisthesis (mean age, 13.8 years). One hundred forty-five patients were treated with surgical fusion, and 82 were followed conservatively. Patients were followed for a mean of 16 years. These authors found that the incidence of ALD was not influenced by the presence or absence of a fusion. Furthermore, when such changes were noted, there were no statistically significant correlations between the number of degenerative disks, the severity of ALD, or the subjective symptoms of low back pain. ${ }^{87}$ These results are particularly compelling when considering the study cohort of young otherwise healthy patients without global degenerative disease.

More recently, Kumar et $\mathrm{al}^{88}$ studied a group of 28 patients who had been treated with lumbar fusion 30 years previously and compared them with age- and sex-matched controls who had undergone lumbar microdiskectomy with or without fusion during the same time period. They, too, found that though the fusion group had a higher incidence of radiographic changes at adjacent segments, functional outcomes as measured by SF-36 and ODI were statistically no different in the 2 groups. ${ }^{88}$ While each of the aforementioned series had extensive clinical follow-up, they represent a mixture of retrospective, case-control, and prospective cohort designs. None of the studies were specifically powered to make statistically significant conclusions regarding the natural history and/or risk of ALD in both nonfused and fused populations.

The debate over the clinical relevance of fusion-induced ALD calls into question one of the theoretic indications for lumbar arthroplasty over fusion. In fact, while arthroplasty is designed to treat low back pain caused by degenerative disease, several differences between fusion and arthroplasty should be clarified to understand the specific indications for the latter. First, fusion across a motion segment should eliminate pain deriving from any spinal pain generator, including the disk space, facets, and associated structures. Given that arthroplasty only addresses the disk space and does not eliminate motion, the procedure is not designed to eliminate pain from sources outside the disk (eg, facet arthropathy). ${ }^{76}$ Second, arthroplasty is not designed to stabilize the spine; therefore, patients with translational deformity, particularly spondylolisthesis, are not good candidates for the procedure. ${ }^{89,90}$ Third, because arthroplasty is designed to maintain if not restore physiologic motion at the disk space, patients with minimal- 
to-no segmental motion secondary to degenerative or pathologic (eg, diffuse idiopathic skeletal hyperostosis, ankylosing spondylitis) segmental autofusion are not appropriate candidates for the procedure. As Bertagnoli and Kumar ${ }^{89}$ described, the ideal patient for lumbar disk arthroplasty has refractory low back pain, a single level of disk disease, $>4 \mathrm{~mm}$ of retained disk space height in the index level, no evidence of facet arthropathy, intact posterior elements, and no neurologic deficit. In a recent review, ${ }^{91}$ Simmons noted that such patients are rare-fewer than $7 \%$ of those receiving surgical intervention for degenerative low back pain would be potential candidates for arthroplasty based on the Charité Artificial Disk (DePuy Spine; Raynham, Massachusetts; see below) exclusion criteria. ${ }^{76}$ Ultimately, in seeking to replicate or augment the function of the normal spinal elements, a lumbar arthroplasty device must take into consideration both the quantity and quality of motion that occurs across the replaced joint.

The simplest but most relevant parameter for evaluating the biomechanical effectiveness of an arthroplasty device is the physiologic ROM, defined as the amount of motion possible across the joint at a prechosen nondestructive load. ROM can be evaluated in terms of translation or rotation about any axis. Angular ROM is more pertinent for rotational motion (eg, flexion/extension), whereas linear ROM is more pertinent for translational motion (eg, axial translation during loading). Although challenging to precisely define in the clinical setting, the effectiveness of the arthroplasty device is measured by comparing appropriate ROM before and after arthroplasty with the normal range for a given lumbar level. (Replicating the preoperative ROM for the level of interest is not advantageous given that the level is already abnormal.) For the arthroplasty to be effective, postarthroplasty ROM should be at least proportionally equivalent to normal. ${ }^{85}$

The AOR is next in importance to the ROM as a parameter for evaluating lumbar arthroplasty. The AOR is the line in space about which rotation occurs during motion of the spine. In purely linear motions (eg, compression, anteroposterior translation), the AOR is at infinity. During more common bending and twisting motions, the AOR lies in or near the disk space. Most important, the AOR is not a fixed point. Rather, the path or "centrode" of the AOR must be evaluated over a complete movement. This complexity can hamper precise evaluation in vivo, where $2 \mathrm{D}$ AOR approximations are taken from $x$-ray data. In vitro, the use of optical markers allows for precise (3D) observations, though loads applied in such a setting are a simplification of true in vivo loading. A spine in which clinically successful arthroplasty has been applied may have exactly the same ROM as the preoperative condition but may have shifted the AOR to a physiologic location. Ultimately, preservation and/or restoration of both normal ROM and $\mathrm{AOR}$ are required to declare an arthroplasty device effective. $^{85}$

"Coupling" refers to secondary motion that occurs in addition to the primary expected motion at a joint. ${ }^{92}$ The best known pattern of coupling in the lumbar spine is the coincident lateral bending that occurs during axial rotation, as a consequence of the sloped facet joints. ${ }^{93}$

For example, during primary axial rotation to the left, the upper lumbar spine bends laterally toward the left and the lower lumbar spine bends laterally toward the right as coupled motions. Coupling is an important biomechanical parameter because it indicates the 3D quality of spine motion. Lumbar arthroplasty should maintain the normal coupling pattern of the spine to minimize bony tissue stress and resultant facet hypertrophy and osteophyte formation. Not surprisingly, coupling properties explain why the AOR is not perpendicular to the plane of primary motion.

Most important, lumbar arthroplasty devices are designed to mimic the biomechanics of an intact motion segment but not recapitulate the biomechanics of the natural disk. Attempts to recapitulate the natural disk by using a flexible elastomeric prosthesis, such as the AcroFlex Lumbar Disk (DePuy Spine), were met with early mechanical failure, very poor clinical outcomes, and removal from the market. ${ }^{94}$ The alternative approach has been to change the nature of the disk from a deformable cushion to a sliding rotational joint. The sliding joint arthroplasty has greater ROM than a flexible core ${ }^{71}$ and relies more on native tissues to limit ROM, reducing the mechanical requirements of the arthroplasty. ${ }^{85}$

While multiple different lumbar prostheses have been available and approved for use in the European market (with many subsequently withdrawn), Investigational Device Exemption trials in the United States have led to FDA approval for the Charité (III) Artificial Disk (DePuy Spine) and multiple iterations of the ProDisc design (successive generations include ProDisc I, ProDisc II, and ProDisc-L; Synthes Spine, Paoli, Pennsylvania) (Table). ${ }^{95,96}$ Both are sliding joint arthroplasty devices and are placed following complete diskectomy via anterior retroperitoneal approaches to the lumbar spine. The Charité was designed in the early 1980s and is currently approved for single-level DDD from L4 to S1. It is composed of cobalt chromium endplates and an UHMWPE mobile sliding core. ${ }^{97}$ The ProDisc was designed in the late 1980s and is similarly composed of cobalt chromium molybdenum endplates with a UHMWPE core. The ProDisc device, however, was developed as a semiconstrained ball-and-socket articular design and fixes the AOR of the motion segment regardless of loading technique.

By contrast, the mobile core of the unconstrained Charité prosthesis makes it possible for the AOR to shift anteriorly during extension and posteriorly during flexion. This pattern more successfully recreates the AOR observed in the normal native spine at L4-5 and L5-S1 in vitro. ${ }^{85}$ The better ability of the Charité to allow the joint to find its natural AOR has been described as its most significant biomechanical advantage over the ProDisc. ${ }^{98}$ As might be anticipated from its semiconstrained design, the advantage of the ProDisc over the Charite appears to be its improved ability to limit anteroposterior translational ROM in response to shear loads, thereby theoretically providing greater stability. ${ }^{99}$ Of particular concern in both arthroplasty devices, however, is the unconstrained nature of axial rotation. In this mode, the arthroplasty relies heavily on the remaining annulus and posterior elements to resist motion, providing only a guiding effect to ensure that the facets interact squarely. Fortunately, in vitro modeling has shown the facets to be potent resistors of axial rotation. ${ }^{100}$

As of 2010, two RCTs have been conducted specifically to address the safety and efficacy of lumbar arthroplasty versus lumbar fusion in patients with symptomatic lumbar DDD. While 16 prospective comparative cohort studies were con- 

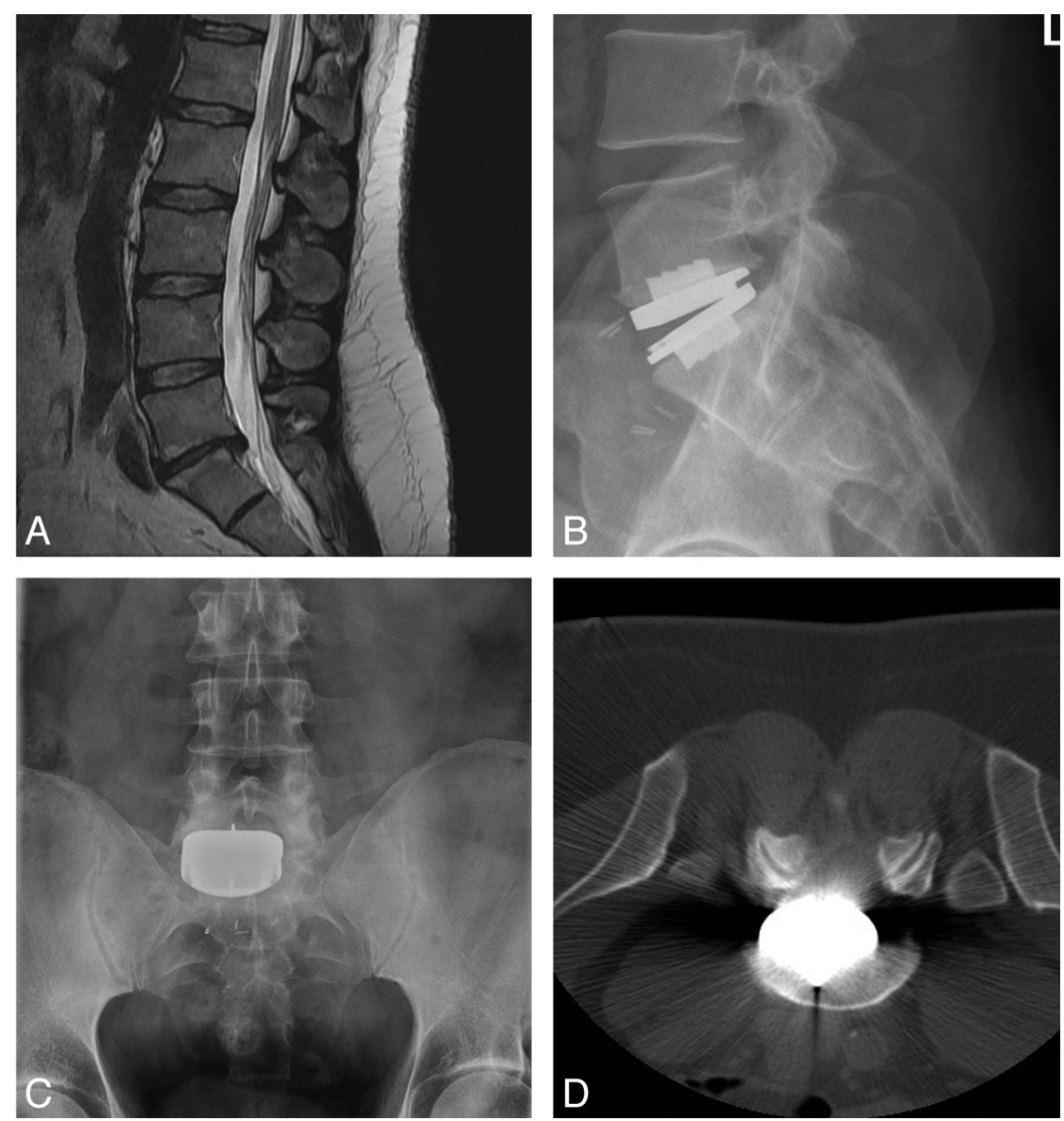

Fig 4. Case illustrating the importance of device positioning. A 37-year-old man with prior history of noninstrumented L5-S1 microdiskectomy, now presenting with axial back pain. $A$, Sagittal T2-weighted MR image depicting degenerative disk disease at the previously operated level. Normal segmental motion without radiographically detectable instability was identified on preoperative flexion/extension dynamic radiographs. $B$ and $C$, Postoperative lateral $(B)$ and anteroposterior $(C)$ views depicting the off-midline position of the ProDisc- $L$ device. At the time of device placement, visualization of the L5-S1 level was limited due to immobile vascular structures. $D$, The patient awoke with right $S 1$ radicular pain attributable to foraminal encroachment from the device as seen on this axial CT scan. The patient failed a short course of conservative management and ultimately required a right-sided L5-S1 hemilaminotomy, foraminotomy, and partial facetectomy for relief of symptoms.

ducted in the same period, the strength of their conclusions regarding efficacy (by design) are inferior to that of an RCT. ${ }^{64}$ As such, we discuss their results only when addressing device safety and complications.

The Charité trial, which was designed as a noninferiority trial, randomized 304 patients to either arthroplasty with the Charite III disk $(n=205)$ or anterior interbody fusion with the BAK (Zimmer Spine, Minneapolis, Minnesota) cage $(n=$ 99) with follow-ups of 2 and 5 years. ${ }^{90,101}$ Inclusion criteria were single-level symptomatic DDD at L4-S1, back and/or leg pain without radiculopathy, VAS $\geq 40$, ODI $\geq 30$, and failure after $\geq 6$ months of conservative treatment. Exclusion criteria were significant and included previous lumbar fusion or fracture, osteoporosis, facet joint arthrosis, collapsed disk space, spinal stenosis, spondylolisthesis of $\geq 3 \mathrm{~mm}$, and scoliotic deformity of $\geq 11^{\circ}$, among others. The primary outcomes were pain (VAS), functional impairment (ODI), and overall clinical success (defined by using 4 criteria: $\geq 25 \%$ improvement in ODI, no device failure, no major complication, and no neurologic deterioration).

As a secondary outcome, patient satisfaction was measured. The comparative improvements in pain scores $(-40.6$ versus -34.1 , arthroplasty versus fusion) and functional impairment ( -24.3 versus $-21.6 \%$, arthroplasty versus fusion) were not statistically different at 2 -year follow-up. These findings were recapitulated at 5-year follow-up. Composite clinical success percentages revealed that the Charite group was noninferior to the lumbar fusion group both at 2-year (57.1 versus $46.5 \%, P<.0001$ ) and 5 -year (57.8 versus $51.2 \%, P<$ $.04)$ follow-ups. Patient satisfaction scores were significantly better in the Charité group (73.7\%) at 2-year follow-up compared with the control group $(53.1 \%, P<.002)$. Five-year follow-up satisfaction scores were broadly in line with 2 -year results, though these data were drawn from only $57 \%$ of the originally randomized population and were thought to be highly biased. ${ }^{64}$ Radiographic analysis by McAfee et $\mathrm{al}^{72} \mathrm{dem}$ onstrated maintenance of flexion/extension ROM in the Charité group with a mean $\mathrm{ROM}$ of $7.5^{\circ}$ versus a baseline value of $6.6^{\circ}$.

Complications can be separated into those related to the surgical approach (eg, vascular injury, nerve root injury, retrograde ejaculation), prosthesis/fusion failure (eg, subsidence, osteolysis, migration, implant fracture, endplate fracture, pseudoarthrosis), donor-site complications, and miscellaneous (eg, infection, pain) (Fig 4). Blumenthal et $\mathrm{al}^{90}$ described overall complication rates in the Charité trial as $29.1 \%$ for arthroplasty and $50.2 \%$ for fusion at 2-year follow-up, though the FDA report on the trial noted overall adverse event 
percentages of $\sim 75 \%$ for both groups. ${ }^{95}$ This discrepancy is most likely a by-product of a more exhaustive definition of "adverse events" by the FDA. Geisler et al ${ }^{102}$ examined neurologic complications (eg, dysesthesia, pain, index-level motor deficit) and found no difference (16.6\% for arthroplasty versus $17.2 \%$ for fusion, $P>.3$ ) between the 2 groups. Device failures necessitating repeat operations have been reported between $5.4 \%$ and $6.3 \%$ for arthroplasty and $9.1 \%$ and $10.1 \%$ for fusion at 2-year follow-up. ${ }^{90,103}$

The ProDisc trial, also designed as a noninferiority trial, randomized 236 patients to either arthroplasty with the ProDisc-L device $(n=161)$ or to lumbar circumferential fusion (anterior interbody fusion with femoral ring allograft and posterolateral fusion with autologous iliac crest bone graft and pedicle screws) $(n=75) .{ }^{104}$ Outcomes were reported with 2-year follow-up. Inclusion and exclusion criteria were similar to those of the Charite trial. Clinical success was defined by using a combination of 4 clinical and 6 radiographic outcomes as required by the FDA (ie, ODI increase $\geq 15 \%$, SF-36 improvement, no repeat operation to revise ProDisc or fusion, no neurologic injury, no device migration, no subsidence, no loss of disk height of $>3 \mathrm{~mm}$, among others). Pain (VAS) and functional impairment were additional primary outcomes. Although the clinical success (as defined above) rate was reported as significantly better in the ProDisc (54.3\%) than in the fusion group $(40.8 \%)(P=.044)$, again demonstrating noninferiority of the arthroplasty device, it is unclear even from the 2007 Zigler et al ${ }^{104}$ publication what statistical testing was applied to derive this calculation. As a consequence, this is considered a highly biased result. ${ }^{64}$

There were no significant differences with respect to mean functional impairment change $(-28.9$ versus $-22.9 \%$, arthroplasty versus fusion) and pain score change ( -39 versus -32 , arthroplasty versus fusion). The overall complication rates reported by Zigler et $\mathrm{al}^{104}$ were similar between the 2 groups: $7.3 \%$ and $6.3 \%$ for arthroplasty and fusion, respectively. Similar to the Charite trial, the FDA report on the ProDisc trial noted adverse event rates of $\sim 85 \%$ for both groups ("FDA Approval ProDisc," 2006 ${ }^{96}$ ). Repeat operation rates were statistically no different when comparing the arthroplasty group (3.7\%) and controls $(5.4 \%) .^{104}$

Numerous concerns regarding design and outcome methodology in both the Charite and ProDisc trials have been described. To begin, the selection of the BAK fusion in the control group for the Charité trial has been criticized by multiple authors. $^{76,105,106}$ While the BAK cages were the only FDAapproved interbody devices available at the time the study was designed and most closely resembled lumbar disk arthroplasty in terms of approach-related morbidity, the greatest success observed with BAK cages for interbody fusion had been in patients with collapsed disk spaces. ${ }^{107}$ Unfortunately, patients with disk space heights of $<4 \mathrm{~mm}$ were excluded from the Charite trial, and this decision caused bias against the control group. In fact, the results obtained in the fusion group were very poor (clinical success rate, $46.5 \%$ ) compared with other contemporary series of anterior lumbar interbody fusion in properly selected patients (equivalent clinical success rate, $85 \%-95 \%) .^{107,108}$

Second, both the Charite and ProDisc trials have been cited for their liberal ODI increase requirement as a component of clinical success (Charité, 25\%; ProDisc, 15\%). Recent consensus suggests that a 30\% ODI increase defines clinically relevant improvement for conservative interventions and that this benchmark should be further elevated for more investigational and/or costly procedures. ${ }^{109}$ Re-stratification of clinical success rates in both trials based on a 30\%-35\% ODI benchmark has been suggested as a means of clarifying the clinical relevance of the data. ${ }^{64}$ Third, the means by which pain scores were incorporated as an outcome measure has been challenged. Resnick and Watters ${ }^{76}$ noted that neither trial incorporated pain relief or opioid use into the definition of clinical success, yet $64 \%$ of those judged to have achieved such success in the Charite trial were using narcotic pain medications 24 months following surgery. ${ }^{90}$ Furthermore, in the ProDisc trial, given that ODI and VAS scores do not account for pain location, there is high likelihood of bias against the control group given the increased pain related to the harvest of the iliac crest autograft and the combined anteroposterior fusion. ${ }^{64}$ Last, the 2-year and 5-year maximum follow-up periods for the 2 trials are likely inadequate, particularly given the relatively young age (mean, $\sim 39$ years) of the trial populations as well as the unknown in vivo life span of a lumbar arthroplasty device. ${ }^{85}$

\section{Summary}

At the present time, there is insufficient evidence to support the superiority or routine use of lumbar arthroplasty for symptomatic lumbar degenerative disk disease, even in the highly selected populations that meet exclusion criteria for the placement of these devices. Improved outcomes related to pain and functional status versus fusion have not been reliably reported in the short or long term. Most important, the true incidence of ALD attributable directly to fusion in the lumbar spine remains unclear, and significant reductions in the development of ALD following fusion versus arthroplasty have not been demonstrated. The authors of this review again speculate that evidence demonstrating the superiority of lumbar arthroplasty over fusion is unlikely to be generated. The necessary stringency of study design, study population size, the development of further device modifications, and the need for longitudinal follow-up may no longer be possible in the current era of device cost containment.

Disclosures: Steven W. Chang-Research Support (including provision of equipment or materials): Medtronic, Details: institutional funding received for biomechanical studies of lumbar stability after posterolateral versus lateral fusion constructs; Speaker Bureau: Stryker Spine, Details: educational consultant for physician seminars and corporate educational series; Other Financial Relationships: Johnson \& Johnson, Details: 2010 resident educational course speaker fees (Boston, Massachusetts).

\section{References}

1. Cloward RB. Vertebral body fusion for ruptured cervical discs. Am J Surg 1959;98:722-27

2. Bailey RW, Badgley CE. Stabilization of the cervical spine by anterior fusion. J Bone Joint Surg Am 1960;42-A:565-94

3. Robinson RA. The problem of neck pain: its alleviation by anterior removal of intervertebral disc with interbody fusion in the cervical spine. J Med Assoc State Ala 1963;33:1-14

4. Smith GW, Robinson RA. The treatment of certain cervical-spine disorders by anterior removal of the intervertebral disc and interbody fusion. $J$ Bone Joint Surg Am 1958;40-A:607-24

5. Chiles BW 3rd, Leonard MA, Choudhri HF, et al. Cervical spondylotic myelopathy: patterns of neurological deficit and recovery after anterior cervical decompression. Neurosurgery 1999;44:762-69, discussion 769-70

6. Bohlman HH, Emery SE, Goodfellow DB, et al. Robinson anterior cervical 
discectomy and arthrodesis for cervical radiculopathy: long-term follow-up of one hundred and twenty-two patients. J Bone Joint Surg Am 1993;75:1298307

7. Fernström U. Arthroplasty with intercorporal endoprosthesis in herniated disc and in painful disc. Acta Chir Scand Suppl 1966;357:154-59

8. Reitz H, Joubert MJ. Intractable headache and cervico-brachialgia treated by complete replacement of cervical intervertebral discs with a metal prosthesis. S Afr Med J 1964;38:881-84

9. Baaj AA, Uribe JS, Vale FL, et al. History of cervical disc arthroplasty. Neurosurg Focus 2009;27:E10

10. Le H, Thongtrangan I, Kim DH. Historical review of cervical arthroplasty. Neurosurg Focus 2004;15 17:E1

11. Bartolomei JC, Theodore N, Sonntag VK. Adjacent level degeneration after anterior cervical fusion: a clinical review. Neurosurg Clin NAm 2005;16:575$87, \mathrm{v}$

12. Wu W, Thuomas KA, Hedlund R, et al. Degenerative changes following anterior cervical discectomy and fusion evaluated by fast spin-echo MR imaging. Acta Radiol 1996;37:614-17

13. Goffin J, Geusens E, Vantomme N, et al. Long-term follow-up after interbody fusion of the cervical spine. J Spinal Disord Tech 2004;17:79-85

14. Lunsford LD, Bissonette DJ, Jannetta PJ, et al. Anterior surgery for cervical disc disease. Part 1. Treatment of lateral cervical disc herniation in 253 cases. J Neurosurg 1980;53:1-11

15. Hilibrand AS, Carlson GD, Palumbo MA, et al. Radiculopathy and myelopathy at segments adjacent to the site of a previous anterior cervical arthrodesis. J Bone Joint Surg Am 1999;81:519-28

16. Eck JC, Humphreys SC, Lim TH, et al. Biomechanical study on the effect of cervical spine fusion on adjacent-level intradiscal pressure and segmental motion. Spine (Phila Pa 1976) 2002;27:2431-34

17. Hwang SH, Kayanja M, Milks RA, et al. Biomechanical comparison of adjacent segmental motion after ventral cervical fixation with varying angles of lordosis. Spine J 2007;7:216-21

18. Fuller DA, Kirkpatrick JS, Emery SE, et al. A kinematic study of the cervical spine before and after segmental arthrodesis. Spine (Phila Pa 1976) 1998;23: $1649-56$

19. Dmitriev AE, Cunningham BW, Hu N, et al. Adjacent level intradiscal pressure and segmental kinematics following a cervical total disc arthroplasty: an in vitro human cadaveric model. Spine (Phila Pa 1976) 2005;30:1165-72

20. Chang UK, Kim DH, Lee MC, et al. Changes in adjacent-level disc pressure and facet joint force after cervical arthroplasty compared with cervical discectomy and fusion. J Neurosurg Spine 2007;7:33-39

21. Chang UK, Kim DH, Lee MC, et al. Range of motion change after cervical arthroplasty with ProDisc-C and prestige artificial discs compared with anterior cervical discectomy and fusion. J Neurosurg Spine 2007;7:40-46

22. DiAngelo DJ, Foley KT, Morrow BR, et al. In vitro biomechanics of cervical disc arthroplasty with the ProDisc-C total disc implant. Neurosurg Focus 2004; $17:$ E7

23. Auerbach JD, Jones KJ, Fras CI, et al. The prevalence of indications and contraindications to cervical total disc replacement. Spine J 2008;8:711-16

24. McAfee PC. The indications for lumbar and cervical disc replacement. Spine J 2004;4(6 suppl):177S-81S

25. Villavicencio AT, Burneikiene S, Pashman R, et al Spinal artificial disc replacement: cervical arthroplasty. Part II. Indications, surgical technique, complications. Contemporary Neurosurgery 2007;29:1-6

26. Meyer B. Spinal arthroplasty is here to stay: editorial. Acta Neurochir (Wien) 2010;152:405-07

27. Sekhon L. Cervicothoracic junction arthroplasty after previous fusion surgery for adjacent segment degeneration: case report. Neurosurgery 2005; 56(1 suppl):E205, discussion E205

28. Sekhon LH, Sears W, Duggal N. Cervical arthroplasty after previous surgery: results of treating 24 discs in $\mathbf{1 5}$ patients. J Neurosurg Spine 2005;3:335-41

29. Phillips FM, Allen TR, Regan JJ, et al. Cervical disc replacement in patients with and without previous adjacent level fusion surgery: a prospective study. Spine (Phila Pa 1976) 2009;34:556-65

30. Mobbs RJ, Mehan N, Khong P. Cervical arthroplasty for myelopathy adjacent to previous multisegmental fusion. J Clin Neurosci 2009;16:150-52

31. Cunningham BW, Hu N, Zorn CM, et al. Comparative fixation methods of cervical disc arthroplasty versus conventional methods of anterior cervical arthrodesis: serration, teeth, keels, or screws? J Neurosurg Spine 2010;12: 214-20

32. Fekete TF, Porchet F. Overview of disc arthroplasty: past, present and future. Acta Neurochir (Wien) 2010;152:393-404

33. Villavicencio AT, Burneikiene S, Pashman R, et al. Spinal artificial disc replacement: cervical arthroplasty. Part I. History, design, and types of artificial discs. Contemporary Neurosurgery 2007;29:1-6

34. Stanton P, Eck J. Materials and design characteristics of cervical arthroplasty devices. Techniques in Orthopaedics 2010;25:93-96

35. Mehren C, Suchomel P, Grochulla F, et al. Heterotopic ossification in total cervical artificial disc replacement. Spine (Phila Pa 1976) 2006;31:2802-06

36. Sola S, Hebecker R, Knoop M, et al. Bryan cervical disc prosthesis: three years follow-up. Eur Spine J 2005;14(suppl 1):38
37. Sekhon LH, Duggal N, Lynch JJ, et al. Magnetic resonance imaging clarity of the Bryan, Prodisc-C, Prestige LP, and PCM cervical arthroplasty devices. Spine (Phila Pa 1976) 2007;32:673-80

38. Antosh IJ, DeVine JG, Carpenter CT, et al. Magnetic resonance imaging evaluation of adjacent segments after cervical disc arthroplasty: magnet strength and its effect on image quality-clinical article. J Neurosurg Spine 2010: 722-26

39. Jazrawi LM, Kummer FJ, DiCesare PE. Alternative bearing surfaces for total joint arthroplasty. J Am Acad Orthop Surg 1998;6:198-203

40. van Ooij A, Kurtz SM, Stessels F, et al. Polyethylene wear debris and long-term clinical failure of the Charité disc prosthesis: a study of 4 patients. Spine (Phila Pa 1976) 2007;32:223-29

41. Pitzen T, Kettler A, Drumm J, et al. Cervical spine disc prosthesis: radiographic, biomechanical and morphological post mortal findings 12 weeks after implantation-a retrieval example. Eur Spine J 2007;16:1015-20

42. Grupp TM, Meisel HJ, Cotton JA, et al. Alternative bearing materials for intervertebral disc arthroplasty. Biomaterials 2010;31:523-31

43. Hu N, Cunningham BW, McAfee PC, et al. Porous coated motion cervical disc replacement: a biomechanical, histomorphometric, and biologic wear analysis in a caprine model. Spine (Phila Pa 1976) 2006;31:1666-73

44. Phillips FM, Garfin SR. Cervical disc replacement. Spine (Phila Pa 1976) 2005 30(17 suppl):S27-33

45. Galbusera F, Bellini CM, Brayda-Bruno M, et al. Biomechanical studies on cervical total disc arthroplasty: a literature review. Clin Biomech (Bristol, Avon) 2008;23:1095-104. Epub 2008 Jul 16

46. Mummaneni PV, Burkus JK, Haid RW, et al. Clinical and radiographic analysis of cervical disc arthroplasty compared with allograft fusion: a randomized controlled clinical trial. J Neurosurg Spine 2007;6:198-209

47. Heller JG, Sasso RC, Papadopoulos SM, et al. Comparison of Bryan cervica disc arthroplasty with anterior cervical decompression and fusion: clinical and radiographic results of a randomized, controlled, clinical trial. Spine (Phila Pa 1976) 2009;34:101-07

48. Murrey D, Janssen M, Delamarter R, et al. Results of the prospective, randomized, controlled multicenter Food and Drug Administration investigational device exemption study of the ProDisc-C total disc replacement versus anterior discectomy and fusion for the treatment of 1-level symptomatic cervical disc disease. Spine J 2009;9:275-86

49. Botelho RV, Moraes OJ, Fernandes GA, et al. A systematic review of randomized trials on the effect of cervical disc arthroplasty on reducing adjacentlevel degeneration. Neurosurg Focus 2010;28:E5

50. Burkus JK, Haid RW, Traynelis VC, et al. Long-term clinical and radiographic outcomes of cervical disc replacement with the Prestige disc: results from a prospective randomized controlled clinical trial. J Neurosurg Spine 2010;13: $308-18$

51. Bartels RH, Donk R, Verbeek AL. No justification for cervical disk prostheses in clinical practice: a meta-analysis of randomized controlled trials. Neurosurgery 2010;66:1153-60, discussion 1160

52. Sasso RC, Smucker JD, Hacker RJ, et al. Clinical outcomes of Bryan cervical disc arthroplasty: a prospective, randomized, controlled, multicenter trial with 24-month follow-up. J Spinal Disord Tech 2007;20:481-91

53. Steinmetz MP, Patel R, Traynelis V, et al. Cervical disc arthroplasty compared with fusion in a workers' compensation population. Neurosurgery 2008;63: 741-47; discussion 747

54. Nabhan A, Ahlhelm F, Pitzen T, et al. Disc replacement using Pro-Disc C versus fusion: a prospective randomised and controlled radiographic and clinical study. Eur Spine J 2007;16:423-30. Epub 2006 Nov 14

55. Nabhan A, Steudel WI, Nabhan A, et al. Segmental kinematics and adjacent level degeneration following disc replacement versus fusion: RCT with three years of follow-up. J Long Term Eff Med Implants 2009;17:229-36

56. Hacker RJ. Cervical disc arthroplasty: a controlled randomized prospective study with intermediate follow-up results: invited submission from the joint section meeting on disorders of the spine and peripheral nerves, March 2005. J Neurosurg Spine 2005;3:424-28

57. Nabhan A, Al-Yhary A, Ishak B, et al. Analysis of spinal kinematics following implantation of lumbar spine disc prostheses versus fusion: radiological study. J Long Term Eff Med Implants 2007;17:207-16

58. Anderson PA, Sasso RC, Riew KD. Comparison of adverse events between the Bryan artificial cervical disc and anterior cervical arthrodesis. Spine (Phila $\mathrm{Pa}$ 1976) 2008;33:1305-12

59. Jawahar A, Cavanaugh DA, Kerr EJ 3rd, et al. Total disc arthroplasty does not affect the incidence of adjacent segment degeneration in cervical spine: results of 93 patients in three prospective randomized clinical trials. Spine J 2010;10:1043-48

60. van Tulder MW, Koes BW, Bouter LM. A cost-of-illness study of back pain in The Netherlands. Pain 1995;62:233-40, 1995

61. Pengel LH, Herbert RD, Maher CG, et al. Acute low back pain: systematic review of its prognosis. $B M J 2003 ; 327: 323$

62. Frelinghuysen $\mathrm{P}$, Huang RC, Girardi FP, et al. Lumbar total disc replacement Part I. Rationale, biomechanics, and implant types. Orthop Clin North Am 2005;36:293-99

63. Errico TJ. Why a mechanical disc? Spine J 2004;4(6 suppl):151S-57S 
64. van den Eerenbeemt KD, Ostelo RW, van Royen BJ, et al. Total disc replacement surgery for symptomatic degenerative lumbar disc disease: a systematic review of the literature. Eur Spine J 2010;19:1262-80

65. Fritzell P, Hagg O, Wessberg P, et al. 2001 Volvo Award winner in clinical studies: lumbar fusion versus nonsurgical treatment for chronic low back pain: a multicenter randomized controlled trial from the Swedish Lumbar Spine Study Group. Spine (Phila Pa 1976) 2001;26:2521-32, discussion 2532-34

66. Resnick DK, Choudhri TF, Dailey AT, et al. Guidelines for the performance of fusion procedures for degenerative disease of the lumbar spine. Part 7. Intractable low-back pain without stenosis or spondylolisthesis. J Neurosurg Spine 2005;2:670-72

67. Smith JS, Shaffrey CI, Sansur CA, et al. Rates of infection following spine surgery based on 108,419 procedures: a report from the Scoliosis Research Society Morbidity and Mortality Committee. Spine (Phila Pa 1976) 2011;36: $556-63$

68. de Kleuver M, Oner FC, Jacobs WC. Total disc replacement for chronic low back pain: background and a systematic review of the literature. Eur Spine J 2003;12:108-16

69. Freeman BJ, Davenport J. Total disc replacement in the lumbar spine: a systematic review of the literature. Eur Spine J 2006;15(suppl 3):S439-47

70. Deyo RA, Nachemson A, Mirza SK. Spinal-fusion surgery: the case for restraint. N Engl J Med 2004;350:722-26

71. Cunningham BW, Dmitriev AE, Hu N, et al. General principles of total disc replacement arthroplasty: seventeen cases in a nonhuman primate model. Spine (Phila Pa 1976) 2003;28:S118-24

72. McAfee PC, Cunningham B, Holsapple G, et al. A prospective, randomized, multicenter Food and Drug Administration investigational device exemption study of lumbar total disc replacement with the Charité artificial disc versus lumbar fusion. Part II. Evaluation of radiographic outcomes and correlation of surgical technique accuracy with clinical outcomes. Spine (Phila Pa 1976) 2005;30:1576-83, discussion E1388-90

73. Link HD. History, design and biomechanics of the Link SB Charité artificial disc. Eur Spine J 2002;11 (suppl 2):S98-105

74. Szpalski M, Gunzburg R, Mayer M. Spine arthroplasty: a historical review. Eur Spine J 2002;11(suppl 2):S65-84

75. Fairbank J, Frost H, Wilson-MacDonald J, et al. Randomised controlled trial to compare surgical stabilisation of the lumbar spine with an intensive rehabilitation programme for patients with chronic low back pain: the MRC spine stabilisation trial. $B M J$ 2005;330:1233

76. Resnick DK, Watters WC. Lumbar disc arthroplasty: a critical review. Clin Neurosurg 2007;54:83-87

77. Weinhoffer SL, Guyer RD, Herbert M, et al. Intradiscal pressure measurements above an instrumented fusion: a cadaveric study. Spine (Phila Pa 1976) 1995;20:526-31

78. Chow DH, Luk KD, Evans JH, et al. Effects of short anterior lumbar interbody fusion on biomechanics of neighboring unfused segments. Spine (Phila Pa 1976) 1996;21:549-55

79. Kim YE, Goel VK, Weinstein JN, et al. Effect of disc degeneration at one level on the adjacent level in axial mode. Spine (Phila Pa 1976) 1991;16:331-35

80. Rao RD, David KS, Wang M. Biomechanical changes at adjacent segments following anterior lumbar interbody fusion using tapered cages. Spine (Phila $\mathrm{Pa}$ 1976) 2005;30:2772-76

81. Cochran T, Irstam L, Nachemson A. Long-term anatomic and functional changes in patients with adolescent idiopathic scoliosis treated by Harrington rod fusion. Spine (Phila $\mathrm{Pa} 1976$ ) 1983;8:576-84

82. Etebar S, Cahill DW. Risk factors for adjacent-segment failure following lumbar fixation with rigid instrumentation for degenerative instability. $\mathrm{J} \mathrm{Neu}$ rosurg 1999;90(2 suppl):163-69

83. Park P, Garton HJ, Gala VC, et al. Adjacent segment disease after lumbar or lumbosacral fusion: review of the literature. Spine (Phila Pa 1976) 2004;29: $1938-44$

84. Rahm MD, Hall BB. Adjacent-segment degeneration after lumbar fusion with instrumentation: a retrospective study. J Spinal Disord 1996;9:392-400

85. Crawford NR. Biomechanics of lumbar arthroplasty. Neurosurg Clin N Am 2005; 16:595-602, v

86. Frymoyer JW, Hanley E, Howe J, et al. Disc excision and spine fusion in the management of lumbar disc disease: a minimum ten-year followup. Spine (Phila Pa 1976) 1978;3:1-6

87. Seitsalo S, Schlenzka D, Poussa M, et al. Disc degeneration in young patients with isthmic spondylolisthesis treated operatively or conservatively: a longterm follow-up. Eur Spine J 1997;6:393-97
88. Kumar MN, Jacquot F, Hall H. Long-term follow-up of functional outcomes and radiographic changes at adjacent levels following lumbar spine fusion for degenerative disc disease. Eur Spine J 2001;10:309-13

89. Bertagnoli R, Kumar S. Indications for full prosthetic disc arthroplasty: a correlation of clinical outcome against a variety of indications. Eur Spine J 2002;11(suppl 2):S131-36

90. Blumenthal S, McAfee PC, Guyer RD, et al. A prospective, randomized, multicenter Food and Drug Administration investigational device exemptions study of lumbar total disc replacement with the CHARITÉ artificial disc versus lumbar fusion. Part I. Evaluation of clinical outcomes. Spine ( $P$ hila $\mathrm{Pa}$ 1976) 2005;30:1565-75, discussion E1387-91

91. Simmons JW. Inclusion Criteria for Disc Arthroplasty. Philadelphia: North American Spine Society, 2005

92. Goel VK, Winterbottom JM, Weinstein JN, et al. Load sharing among equal spinal elements of a motion segment in extension and lateral bending. J Biomech Eng 1987;109:291-97

93. Panjabi M, Yamamota I, Oxland T, et al. How does posture affect coupling in the lumbar spine? Spine 1989;14:1002-11

94. Fraser RD, Ross ER, Lowery GL, et al. AcroFlex design and results. Spine J 2004;4(6 suppl):245S-51S

95. US Food and Drug Administration. FDA Approval Charité. 2004; http://www. fda.gov/cdrh_docs/pdf4/p040006a.pdf

96. US Food and Drug Administration. FDA Approval ProDisc. 2006; http://www.accessdata.fda.gov/cdrh_docs/pdf5/p050010a.pdf

97. Aryan HE, Acosta FL Jr, Ames CP. The Charité artificial disc: insertion technique. Neurosurg Clin N Am 2005;16:637-50, vii

98. Huang RC, Girardi FP, Cammisa FP Jr, et al. The implications of constraint in lumbar total disc replacement. J Spinal Disord Tech 2003;16:412-17

99. Diangelo D, Foley KT, Morrow B, et al. Biomechanical comparison of the Charité and ProDisc lumbar disc prostheses. In: Proceedings of the Global Symposium on Motion Preservation Technology, 5th Annual Meeting of the International Society for the Advancement of Spine Surgery, New York. May 4-7, 2005

100. Ahmed AM, Duncan NA, Burke DL. The effect of facet geometry on the axial torque-rotation response of lumbar motion segments. Spine (Phila $\mathrm{Pa} 1976$ ) 1990;15:391-401

101. Guyer RD, McAfee PC, Banco RJ, et al. Prospective, randomized, multicenter Food and Drug Administration investigational device exemption study of lumbar total disc replacement with the Charite artificial disc versus lumbar fusion: five-year follow-up. Spine J May 2009;9:374-86. Epub 2008 Sep 19

102. Geisler FH, Blumenthal SL, Guyer RD, et al. Neurological complications of lumbar artificial disc replacement and comparison of clinical results with those related to lumbar arthrodesis in the literature: results of a multicenter, prospective, randomized investigational device exemption study of Charité intervertebral disc-invited submission from the Joint Section Meeting on Disorders of the Spine and Peripheral Nerves, March 2004. J Neurosurg Spine 2004;1:143-54

103. McAfee PC, Geisler FH, Saiedy SS, et al. Revisability of the Charite artificial disc replacement: analysis of 688 patients enrolled in the U.S. IDE study of the Charite artificial disc. Spine (Phila Pa 1976) 2006;31:1217-26

104. Zigler J, Delamarter R, Spivak JM, et al. Results of the prospective, randomized, multicenter Food and Drug Administration investigational device exemption study of the ProDisc-L total disc replacement versus circumferential fusion for the treatment of 1-level degenerative disc disease. Spine (Phila $\mathrm{Pa}$ 1976) 2007;32:1155-62, discussion 1163

105. Mirza SK. Point of view: commentary on the research reports that led to Food and Drug Administration approval of an artificial disc. Spine (Phila $\mathrm{Pa} 1976$ ) 2005;30:1561-64

106. Zindrick MR, Lorenz MA, Bunch WH. Editorial Response to Parts 1 and 2 of the FDA IDELumbar Total Disc Replacement With the Charite ${ }^{\mathrm{TM}}$ Artificial Disc Vs. Lumbar Fusion. Spine (Phila Pa 1976) 2005;30:E388-90

107. Burkus JK, Transfeldt EE, Kitchel SH, et al. Clinical and radiographic outcomes of anterior lumbar interbody fusion using recombinant human bone morphogenetic protein-2. Spine (Phila Pa 1976) 2002;27:2396-408

108. Sasso RC, Kitchel SH, Dawson EG. A prospective, randomized controlled clinical trial of anterior lumbar interbody fusion using a titanium cylindrical threaded fusion device. Spine (Phila Pa 1976) 2004;29:113-22, 2004, discussion 121-22

109. Ostelo RW, Deyo RA, Stratford P, et al. Interpreting change scores for pain and functional status in low back pain: towards international consensus regarding minimal important change. Spine (Phila Pa 1976) 2008;33:90-94 